\title{
Lamentationes Jeremiae Prophetae de Orlando Di Lasso: algumas figuras retórico-musicais na Lamentatio Prima Primi Diei (Feria Quinta In Coena Domini)
}

\author{
Áurea Helena de Jesus Ambiel (UNICAMP) \\ aambiel@hotmail.com
}

Resumo: Este artigo tem como proposta a identificação, na primeira lição das Lamentationes Jeremiae Prophetae, de Orlando Di Lasso (Lamentatio Prima Primi Diei), de figuras retórico-musicais, utilizando a terminologia de época. Para tanto, o trabalho está baseado principalmente na obra Musica Poetica (Rostock, 1606) de Joachim Burmeister, tradução de Benito V. Rivera (Musical Poetics, 1993). A pesquisa faz parte de um projeto de doutorado, que tem como objeto de estudo a obra completa Lamentationes Jeremiae Prophetae (a 5 vozes), que se compõe de três partes: Feria Quinta In Coena Domini, Feria Sexta In Parasceve e Sabbato Sancto. A abordagem analítica de toda a obra deverá seguir a metodologia proposta por Burmeister na sua quinta categoria de análise ("resolução da composição em afetos ou períodos"), ${ }^{1}$ além de conter observações concernentes ao uso de figuras e outros artifícios retórico-musicais, seguindo indicações propostas por autores contemporâneos a Lasso que, em muitos casos, citam trechos de suas obras como exemplos para suas colocações. Com o resultado da pesquisa, espera-se fornecer subsídios analíticos que possam reverter em uma interpretação mais segura e historicamente mais bem fundamentada.

Palavras-chave: Lasso, Burmeister, figuras retórico-musicais, Lamentações, musicologia histórica.

\section{Orlando Di Lasso' s Lamentationes Jeremiae Prophetae: some rhetorical- musical figures in Lamentatio Prima Primi Diei (Feria Quinta In Coena Domini)}

\begin{abstract}
The aim of this article is to identify rhetorical-musical figures in the first lesson of Orlando Di Lasso's Lamentationes Jeremiae Prophetae (Lamentatio Prima Primi Diei) with the terminology used at his period. Thus, the article is based on Joachim Burmeister's Musica Poetica (Rostock, 1606) with the translation into English by Benito V. Rivera (Musical Poetics, 1993).This article is part of a doctoral degree project whose object is the whole Lasso's Lamentationes Jeremiae Prophetae (for five voices) which is divided in three parts: Feria Quinta In Coena Domini, Feria Sexta In Parasceve and Sabbato Sancto. The analytical approach of the whole work must follow the methodology proposed by Burmeister in his fifth category of analysis (sectioning of the piece into affections or periods). ${ }^{2}$ The work also contains observations concerning the use of figures and other rhetorical-musical devices following suggestions which were proposed by authors from the same period of Lasso. These authors, in most cases, used Lasso's works to illustrate their statements. We hope the analytical data provided can help more reliable and historically based performances.
\end{abstract}

Keywords: Lasso, Burmeister, rhetorical-musical figures, Lamentations, historical musicology.

\section{Introdução}

Joachim Burmeister (1564-1629), professor, teórico e compositor, foi um pioneiro no estudo e aplicação das figuras retóricas em música. Em Musical Poetics (BURMEISTER [1606], 1993), o autor explica as figuras retórico-musicais, mencionando frequentemente a obra de Lasso. Um interessante exemplo é a obra In me Transierunt Irae Tuae que Burmeister utiliza como objeto de análise retórica (BURMEISTER [1606], 1993, p.205-207).
Ian D. BENT e Anthony POPLE (1980, v.1, p.530), atribuem a ele, a primeira definição de análise e a primeira proposta de análise formal em música. Segundo BURMEISTER ([1606], 1993, p.201):

Análise Musical é o exame de uma peça, pertencente a um determinado modo e a um determinado tipo de polifonia. A peça será dividida em afetos ou períodos, de maneira que o artifício com o qual cada período se concretiza, pode ser estudado ou adotado para imitação. Existem cinco áreas de análises: (1) investigação do

Recebido em: 26/09/2007 - Aprovado em: 04/04/2008 
modo; (2) investigação do gênero melódico; (3) investigação do tipo de polifonia; (4) consideração da qualidade; (5) secionamento da peça em afetos ou períodos.

0 autor (BURMEISTER [1606], 1993, p. xlix) define afeto musical da seguinte maneira:

Um período numa melodia ou peça harmônica, finalizada por uma cadência, que move e incita os corações dos homens. É um movimento ou algo que traz alegria ou tristeza para a fraqueza humana (como Basilius Faber coloca), sendo tanto encantador, agradável e bem-vindo, como inoportuno e desagradável aos ouvidos e ao coração.

Neste artigo identificam-se algumas figuras retóricomusicais presentes na Lamentatio Prima Primi Diei, que podem ser utilizadas como ferramentas nas investigações posteriores da quinta categoria analítica deste teórico.

\section{Análise da Lamentatio Prima Primi Diei (Elegia Prima, 1-3)}

A obra de Lasso é composta inicialmente em frígio sobre Lá.

Segundo RIVERA e RUHNKE (1980, v.4, p.636), Burmeister "sugeriu uma fascinante taxonomia dos afetos musicais que combinava teoria triádica com o sistema dos doze modos, de uma maneira que prenunciou a tipologia maior-menor. Ele explicou os afetos associados a cada modo em termos da posição dos semitons relativos aos três graus governantes da escala" [a basis, a terça e a quinta].

Os autores acima citados mencionam ainda que, no modo frígio, "ambos os semitons estão na mesma relação para a basis e para a quinta." Como os semitons estão localizados acima da quinta e da basis, ele é considerado "suave, lamentoso e lacrimoso." Desta maneira, através da estrutura da obra (no que diz respeito à relação entre o modo e o afeto a ele relacionado), é possivel perceber a sua própria essência: o lamento.

P. HERREWEGHE (ver documento sonoro) ${ }^{3}$ menciona a respeito da obra de Lasso:

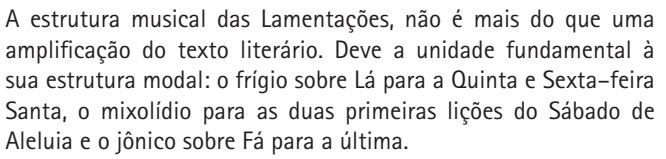

A estrutura musical das Lamentações, não é mais do que uma amplificação do texto literário. Deve a unidade fundamental à sua estrutura modal: o frígio sobre Lá para a Quinta e Sexta-feira Santa, o mixolídio para as duas primeiras lições do Sábado de Aleluia e o jônico sobre Fá para a última.

Se adotarmos a divisão do discurso em três partes, como sugere BURMEISTER em Musical Poetics ([1606], 1993, p.203), ${ }^{4}$ esta primeira lamentação (a abreviação Lam.1.1 significa primeira lamentação, primeiro versículo) pode apresentar: (1) exordium (2) medium (o "corpo da obra") e (3) finis, com a ocorrência de nove seções (Tab.1):

A seguir, identificam-se algumas figuras retóricomusicais, segundo a terminologia de Joachim Burmeister e Athanasius Kircher.

\section{1 - Hypallage}

"Quando uma fuga é introduzida com uma organização [melodicamente] invertida dos intervalos (BURMEISTER [1606], 1993, p.163)." ${ }^{5}$ Ao princípio da obra ocorre a figura de hypallage (Ex.1 seção1, tab1). Um motivo ascendente é trazido pelo tenor I e imitado pelo altus

\begin{tabular}{|c|c|c|c|}
\hline & seção & compassos & texto \\
\hline EXORDIUM & 1 & 1 a 12 & Incipit Lamentatio Jeremiae Prophetae \\
\hline \multirow[t]{6}{*}{ MEDIUM } & 2 & 13 a 18 & Aleph: primeira letra do alfabeto hebraico \\
\hline & 3 & 19 a 43 & $\begin{array}{l}\text { Lam.1:1 } \\
\text { Quo modo sedet sola civitas plena populo! } \\
\text { Facta est quasi vidua domina gentium; } \\
\text { princeps provinciarum facta est sub tributo. }\end{array}$ \\
\hline & 4 & 44 a 49 & Beth:segunda letra do alfabeto hebraico \\
\hline & 5 & 50 a 77 & $\begin{array}{l}\text { Lam.1:2 } \\
\text { Plorans ploravit in nocte, et lacrymae ejus in maxillis ejus; } \\
\text { non est qui consoletur eam, ex omnibus charis ejus; } \\
\text { omnes amici ejus spreverunt eam, et facti sunt ei inimici. }\end{array}$ \\
\hline & 6 & 78 a 82 & Ghimel.terceira letra do alfabeto hebraico \\
\hline & 7 & 83 a 112 & $\begin{array}{l}\text { Lam.1:3 } \\
\text { Migravit Judas propter afflictionem, et multitudinem servitutis; } \\
\text { Habitavit inter gentes, nec invenit requiem; } \\
\text { omnes persecutores ejus apprehenderunt eam inter angustias. }\end{array}$ \\
\hline \multirow[t]{2}{*}{ FINIS } & 8 & 113 a 117 & Jerusalem, Jerusalem \\
\hline & 9 & 118 a 124 & convertere ad Dominum Deum Tuum. \\
\hline
\end{tabular}

Tab.1: Lamentatio Prima Primi Diei (Elegia prima,1-3) de Orlando Di Lasso: divisão tripartida da obra 


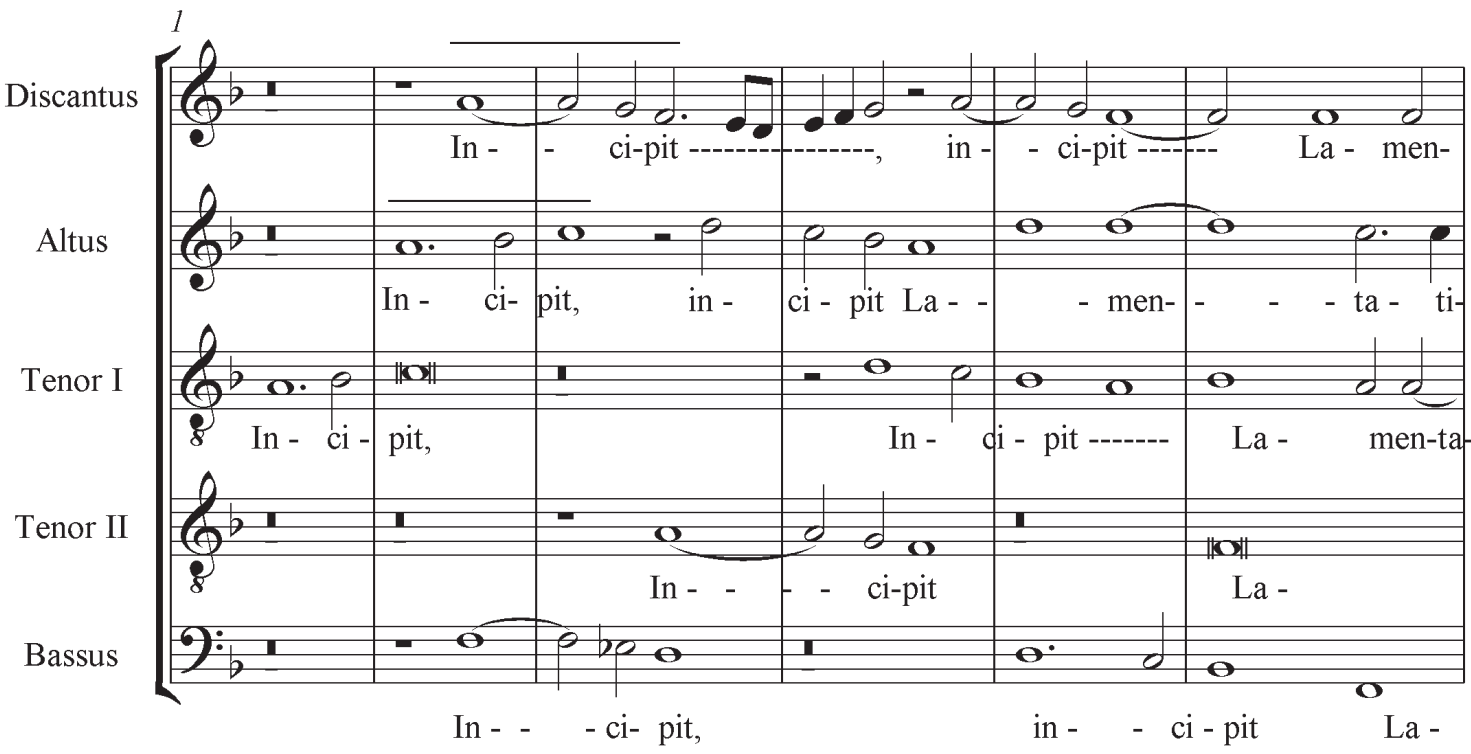

Ex.1 - Hypallage (Incipit) das Lamentationes Jeremiae Prophetae de Orlando Di Lasso.

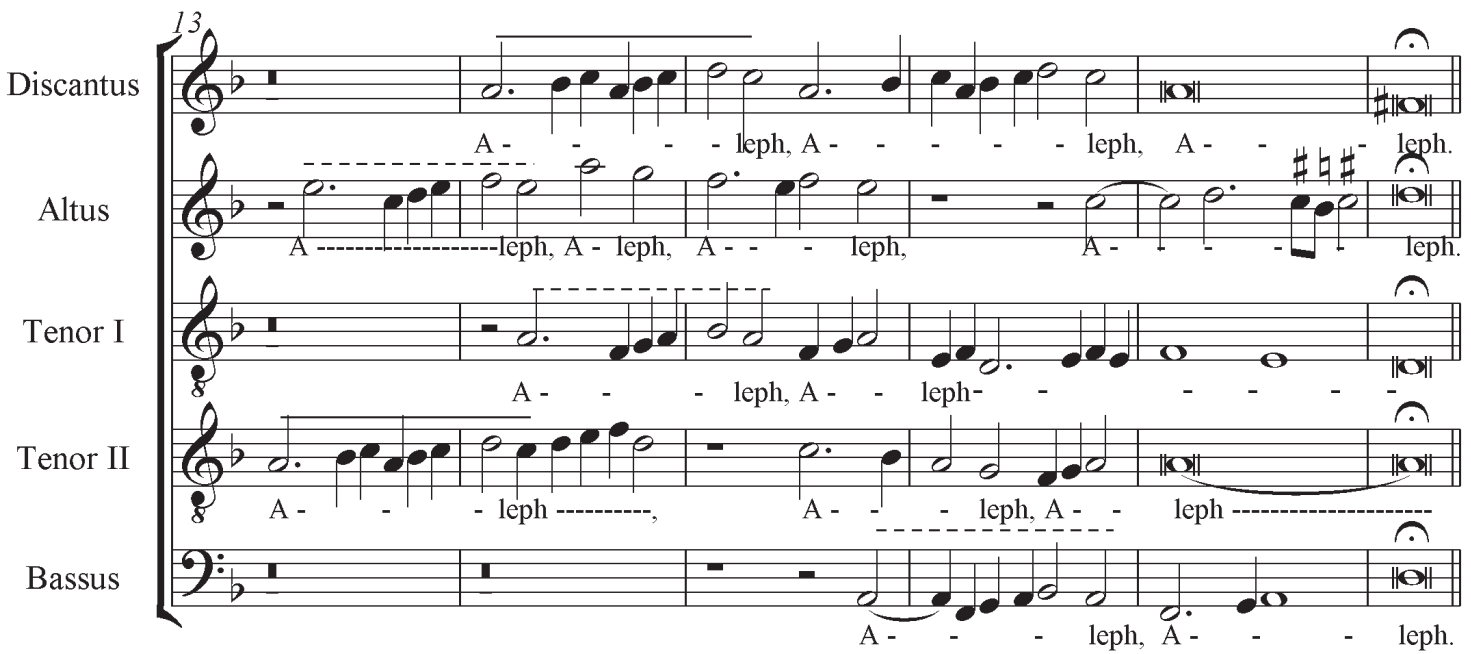

Ex.2- Anaphora (Aleph) das Lamentationes Jeremiae Prophetae de Orlando Di Lasso.

(c. 1-2). A próxima imitação com a palavra incipit (início) ocorre no discantus ${ }^{6}$ e bassus, entretanto, em movimento descendente (c.2-3). Verifica-se então, um movimento contrário entre as vozes de altus e discantus + bassus (c.2-3), o que pode caracterizar a figura de hypallage.

\section{2 - Anaphora}

"É um ornamento que repete modelos de alturas similares em algumas, mas não em todas as vozes da harmonia. Isto acontece na maneira de uma fuga, embora não seja de fato uma fuga" (BURMEISTER [1606], 1993, p.185-187). "ANAPHORA (Kircher) = REPETITIO (Nucius).
A repetição de uma exposição melódica sobre notas diferentes em diferentes partes" (WILSON, BUELOW, HOYT, 1980, v.21, p.264).

Fez-se necessário empregar as definições de anaphora supracitadas, para explicar a ocorrência de algumas figuras retóricas existentes na obra. Foram identificados quatro exemplos da figura. No primeiro, observa-se a repetição de dois motivos diferentes (anaphora I e II) em Aleph (primeira letra do alfabeto hebraico; c.1318; seção 2). É empregada aqui, a definição de Kircher (Ex.2) 
Ocorrem em Aleph dois motivos imitativos ligeiramente diferentes. 0 primeiro, trazido pelo tenor II (c.13-14), melismático, ascende na sua maioria por graus conjuntos; é imitado pelo discantus (c.14-15). Esta primeira figura é chamada anaphora I. Verifica-se o segundo motivo imitativo na voz de altus (c.13-14), denominado anaphora II. Este melisma traz um salto intervalar de terça maior descendente e ascende por graus conjuntos. É imitado pelo tenor l e bassus.

Através de suas entradas imitativas, as figuras de anaphora apresentam caráter de ênfase e reafirmação. 0 transcorrer e o imitar da palavra Aleph nas diversas vozes reforça: está iniciando a lamentação.

0 próximo exemplo de anaphora (Ex.3) ocorre na segunda letra do alfabeto hebraico: Beth (c.44-49; quarta seção; ver Tab.1), que antecede o segundo versículo. Aplica-se a definição de anaphora de Burmeister, para este e os demais exemplos.

Observam-se três entradas deste motivo melismático: tenor II, altus e discantus (c.44-47).

0 terceiro exemplo desta figura (Ex.4) ocorre na terceira letra do alfabeto hebraico (Ghimel; c.78-82; seção 6; ver Tab.1), preparando o próximo versículo.

Motivo melismático imitativo semelhante à Beth (ver exemplo anterior) é, entretanto, descendente e ocorre no tenor II, tenor l e discantus (c.78-82).

Após a análise das três letras hebraicas presentes na Lamentatio Prima, verifica-se que Lasso emprega a mesma figura (anaphora) e procedimento técnico semelhante na abertura dos versículos. A ocorrência do tratamento imitativo e melismático, assim como o emprego de uma mesma figura nas letras hebraicas, prepara o ouvinte à entrada dos versos e dá unidade à obra.

0 quarto exemplo desta figura (Ex.5) ocorre no terceiro versículo (seção 7; ver Tab.1) em habitavit inter gentes (c.92-94).

"Hoje habita entre as nações, sem encontrar repouso" (A BÍBLIA DE JERUSALÉM, 2002, p.1460).

Entradas imitativas de mesma altura ocorrem nas vozes de tenor / e discantus (c.92-94). A textura é mais rarefeita, as vozes entram aos poucos. A imitação ocorre na palavra "habita", as mínimas deste motivo e a sua repetição sugerem movimento, caminhada. Jerusalém habita entre as nações, mas sem a força e o poder de outrora.

\section{3 - Hypotyposis}

Segundo Burmeister ([1606], 1993, p.175), hypotyposis "é aquele ornamento por meio do qual, o senso do texto é tão claramente retratado que fatos inanimados descritos no texto parecem ser conduzidos à vida". Dietrich BARTEL (1997, p.307309) em Musica Poetica comenta a respeito da hypotyposis:
Uma representação musical vivida de imagens encontradas no texto. À hypotyposis é dada a mesma incumbência, tanto na retórica como na música: ilustrar vivida e realisticamente um pensamento ou imagem encontrada no texto. Assim como poderia até ser considerado o recurso composicional mais importante e comum de texto-expressivo da música barroca, é a regra da música poética para deleitar e mover o ouvinte, através de uma representação musical do texto. Tal representação pictórica da palavra torna-se uma marca da música barroca, encontrada em virtualmente toda composição vocal. Literalmente o termo significa uma imitação ou reprodução... Tanto o uso retórico, como o uso retórico-musical desta figura, reflete uma imagem, em vez de expressar um afeto. Enquanto Burmeister inclui a hypotyposis como uma figura que reflete imagens, é a sua pathopoeia ${ }^{7}$ que é usada para expressar musicalmente os afetos... Embora somente Burmeister inclua hypotyposis explicitamente entre as figuras retórico-musicais, Vogt sugere que praticamente todas as outras figuras possam ser usadas como sendo de hypotyposis. ${ }^{8}$

Verifica-se a figura de hypotyposis em Omnes persecutores ejus apprehenderunt eam (Lam.1:3; seção 7; c.100-107; ver Tab.1) no Ex.6.

"Os que a perseguiam alcançaram-na..." ( $A$ BÍBLIA DE JERUSALÉM, 2002, p.1460).

A representação da perseguição pode ser observada através de recursos retórico-musicais indicando movimento:

- tratamento contrapontístico em omnes, apresenta duas entradas similares no tenor I e bassus (ver c.100-102, respectivamente).

- na palavra persecutores, observa-se uma "perseguição" harmônica (Gm $\rightarrow \mathrm{D} \mathrm{Gm} \rightarrow \mathrm{D} \rightarrow \mathrm{Gm} \rightarrow \mathrm{Dm}$ ). Predomínio de mínimas seguidas.

- na voz de discantus alternam-se as notas Sol ${ }^{3}$ e Fá\#\# ${ }^{3}$, o bassus repete as notas Sol ${ }^{1}$ e Ré ${ }^{2}$ e o tratamento das vozes é vertical (ver c.102-103). Aqueles que perseguiam Jerusalém alcançaram-na, aqui termina a perseguição e Jerusalém está em poder do inimigo. Apprehenderunt (c.104-105) traz tratamento homofônico ao início: Jerusalém dominada!

\section{4 - Antitheton (ou Contrapositum)}

Segundo BARTEL (1997, p.199), Kircher (Musurgia L.8, p.145) dá a seguinte definição de antitheton: "é uma passagem musical na qual nós expressamos afetos opostos, como Giacomo Carrissimi contrastou o risonho de Heraclitus com o choroso de Demócrito, ou como Leonus Leoni expressou: 'Eu durmo, mas meu coração vigia'." WILSON, BUELOW e HOYT (1980, v.21, p.268) em Rethoric and Music, também citam a definição de Kircher:

Um contraste musical, para expressar coisas contrárias e opostas, ocorrendo sucessiva ou simultaneamente. Ela pode ser caracterizada por registros contrastantes em uma parte da voz, idéias temáticas contrastantes em uma textura contrapontística, texturas musicais contrastantes, etc. 


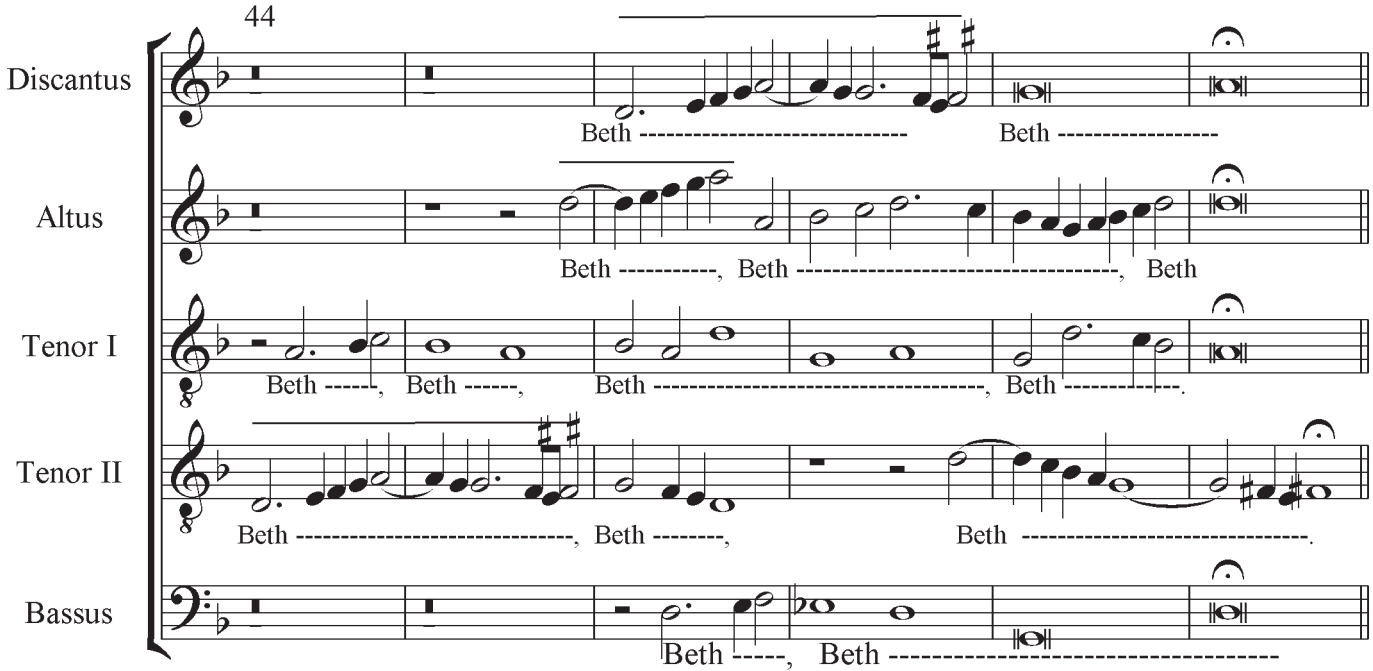

Ex.3 - Anaphora (Beth) das Lamentationes Jeremiae Prophetae de Orlando Di Lasso

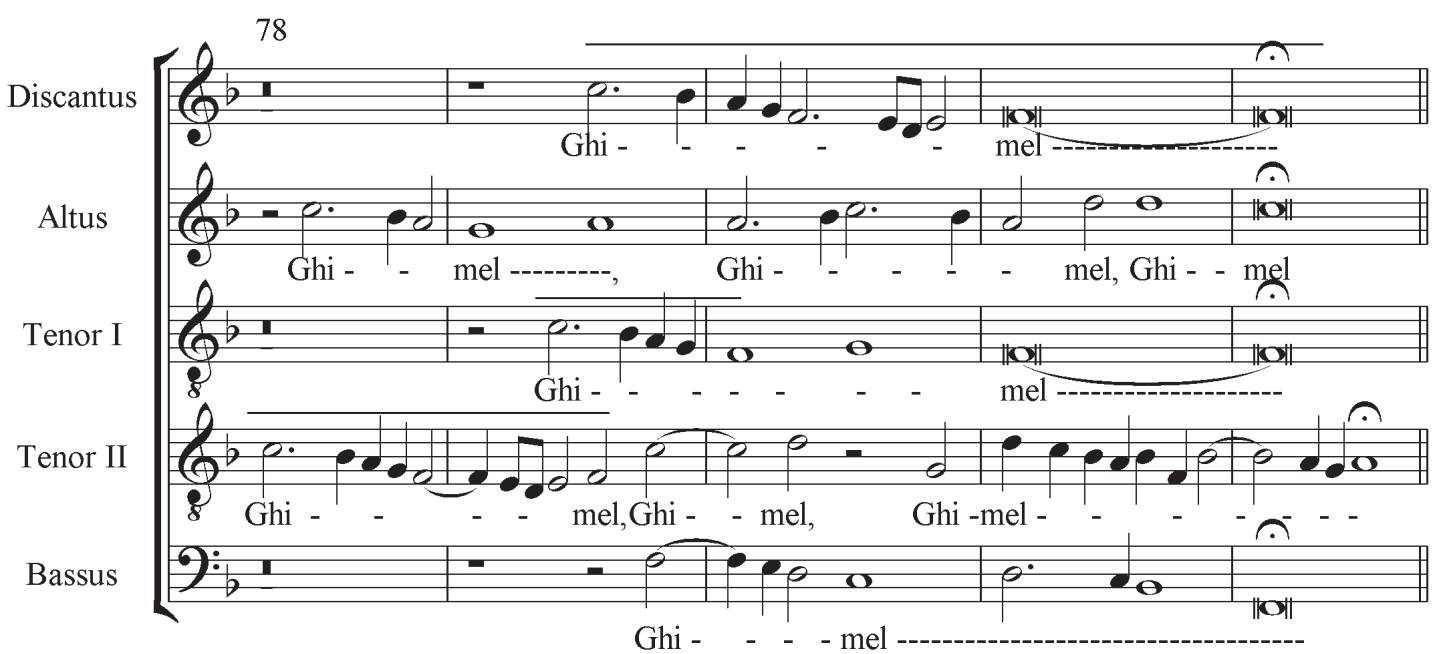

Ex.4 - Anaphora (Ghimel) das Lamentationes Jeremiae Prophetae de Orlando Di Lasso

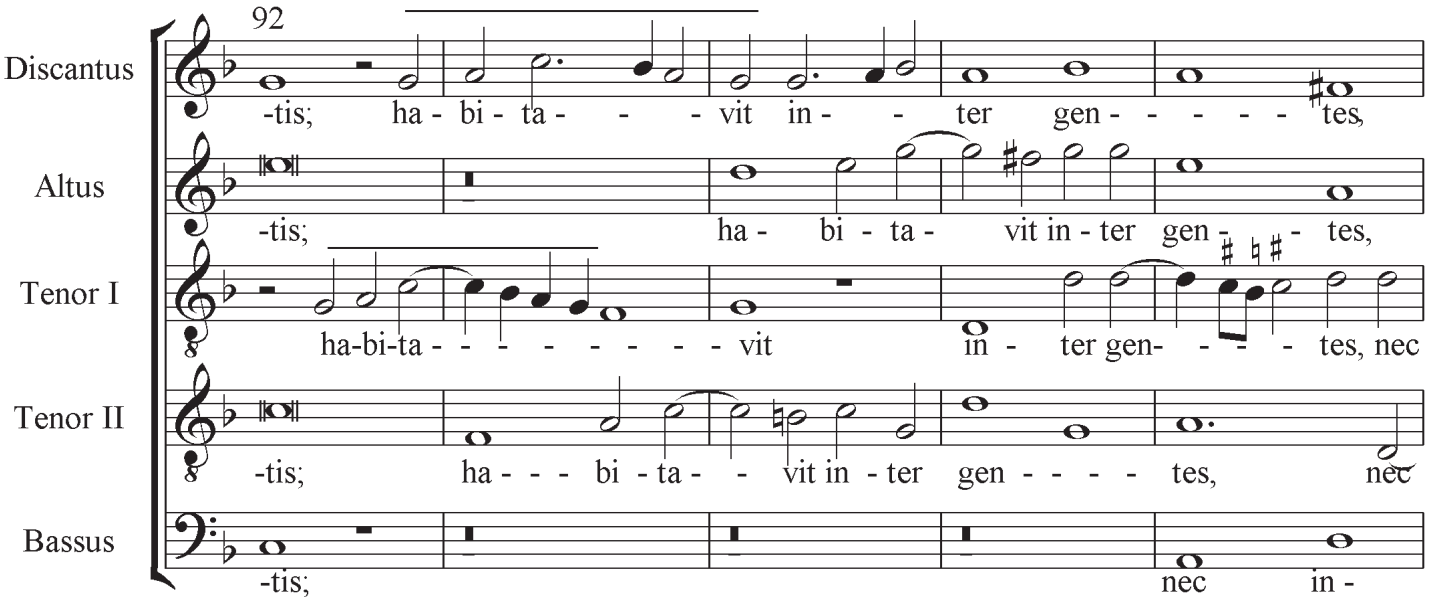

Ex.5 - Anaphora (habitavit inter gentes) das Lamentationes Jeremiae Prophetae de Orlando Di Lasso 

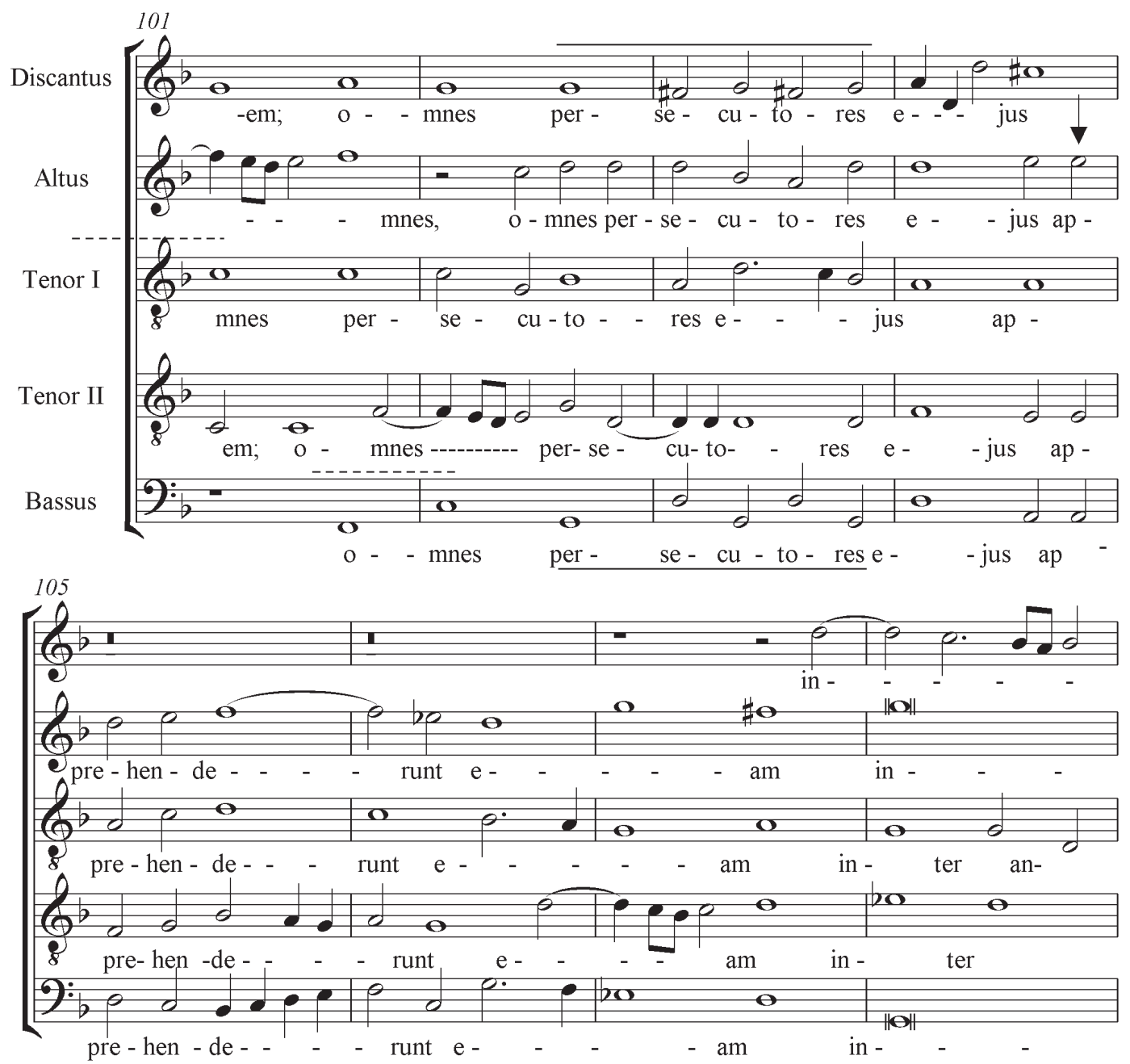

Ex.6 - Hypotyposis (omnes persecutores ejus apprehenderunt eam) das Lamentationes Jeremiae Prophetae de Orlando Di Lasso

Esta figura ocorre no primeiro versículo das lamentações (seção 3; c.19-28; ver Tab.1). Talvez por sugestão poética do próprio texto, Lasso emprega uma figura de contraste: Quomodo sedet sola civitas plena populo! "Como está solitária a cidade outrora populosa!" (Ex.7).

Aqui, "O poeta descreve o estado miserável de Jerusalém (A BÍBLIA DE JERUSALÉM, 2002, p.1460)."9 Ao iniciar a primeira lamentação, verifica-se nitidamente a intenção de contrastar idéias opostas (Tab.2). 0 compositor reserva o contraponto a duas vozes (tenor /l e bassus) à solidão de Jerusalém, enquanto que, um tratamento mais vertical ( 5 vozes) é reservado às partes antecedente e conseqüente. A cidade que antes era habitada (populosa), agora está só (termina em uníssono; c.25).

\begin{tabular}{|l|c|c|}
\hline Quomodo sedet & sola civitas & plena populo \\
\hline Homofonia (5 vozes) & Contraponto (2 vozes) & Homofonia (5 vozes) \\
\hline
\end{tabular}

Tab.2 - Antitheton das Lamentationes Jeremiae Prophetae de Orlando Di Lasso 

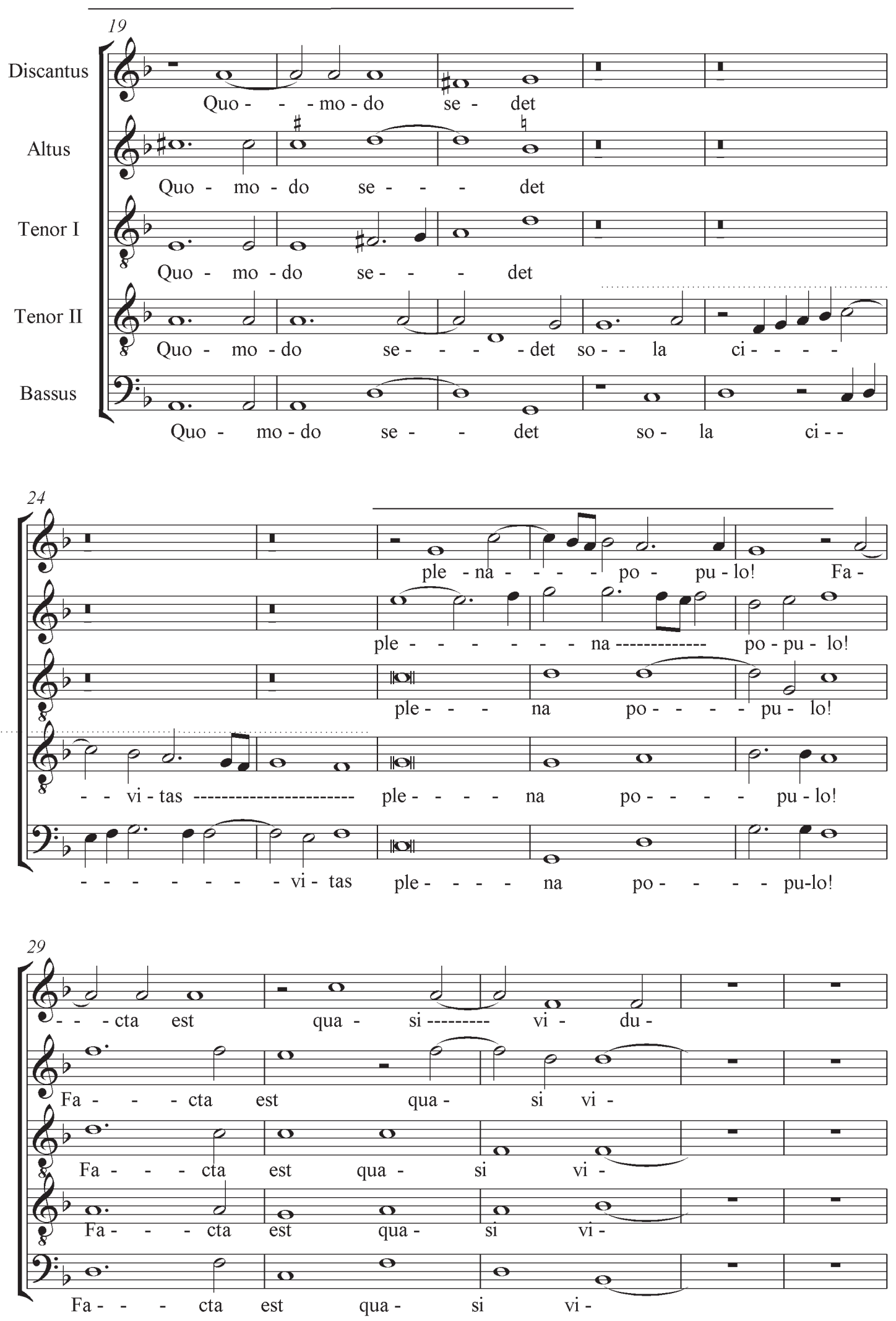

Ex.7- Antitheton (quo modo sedet sola civitas plena populo) das Lamentationes Jeremiae Prophetae de Orlando Di Lasso 


\section{5 - Pathopoeia}

Significa "excitação das paixões." ${ }^{10} \mathrm{~A}$ respeito desta figura, BURMEISTER menciona ([1606],1993, p.175):

É uma figura adaptada para provocar os afetos, que ocorre quando semitons que não pertencem ao modo e nem ao gênero da peça, são empregados e introduzidos de maneira a aplicar os recursos de uma classe à outra. 0 mesmo se mantém quando os semitons, próprios ao modo da peça, são usados mais frequentemente do que é costume.

Em "passa a noite chorando, pelas faces correm-lhe lágrimas" (A BÍBLIA DE JERUSALÉM, 2002, p.1460), a palavra plorans traz a figura de pathopoeia, representada por uma segunda menor (Ex.8). 0 afeto é o da tristeza. A figura é também enfatizada pela tessitura das vozes (não ocorre o emprego de discantus e nem do bassus, mas de vozes centrais: altus, tenor / e II, c.50-53 aproximadamente). 0 melisma em ploravit (altus) também remete à idéia do choro ou lamento. 0 intervalo de segunda menor pode também ser encontrado em lacrymae ejus (discantus, c.56-57).

\section{6 - Pleonasmus}

"É a efusão abundante da harmonia durante a formação de uma cadência, especificamente na parte média. Caracterizado por combinação de symblema e syncope dentro de dois, três ou mais tactus."11 (BURMEISTER [1606], 1993, p.171). Segundo BARTEL (1997, p.365):

Burmeister introduz o termo na Figurenlehre musical, definindoo como uma passagem dissonante (symblema,) que é prolongada através de uma suspensão (syncopa), antes de sua resolução. Ambos, symblema e syncopa, introduzem dissonâncias dentro da estrutura harmônica de uma composição. Isto resulta no exagero ou abundância pretendida, isto é, de dissonâncias. A combinação de notas de passagem e suspensão, estende não somente uma dissonância, mas pode criar ainda outro prolongamento: então, os numerosos pleonasmoi devem estar ligados; a cadência poderia ser estendida sobre dois, três, ou mais compassos.
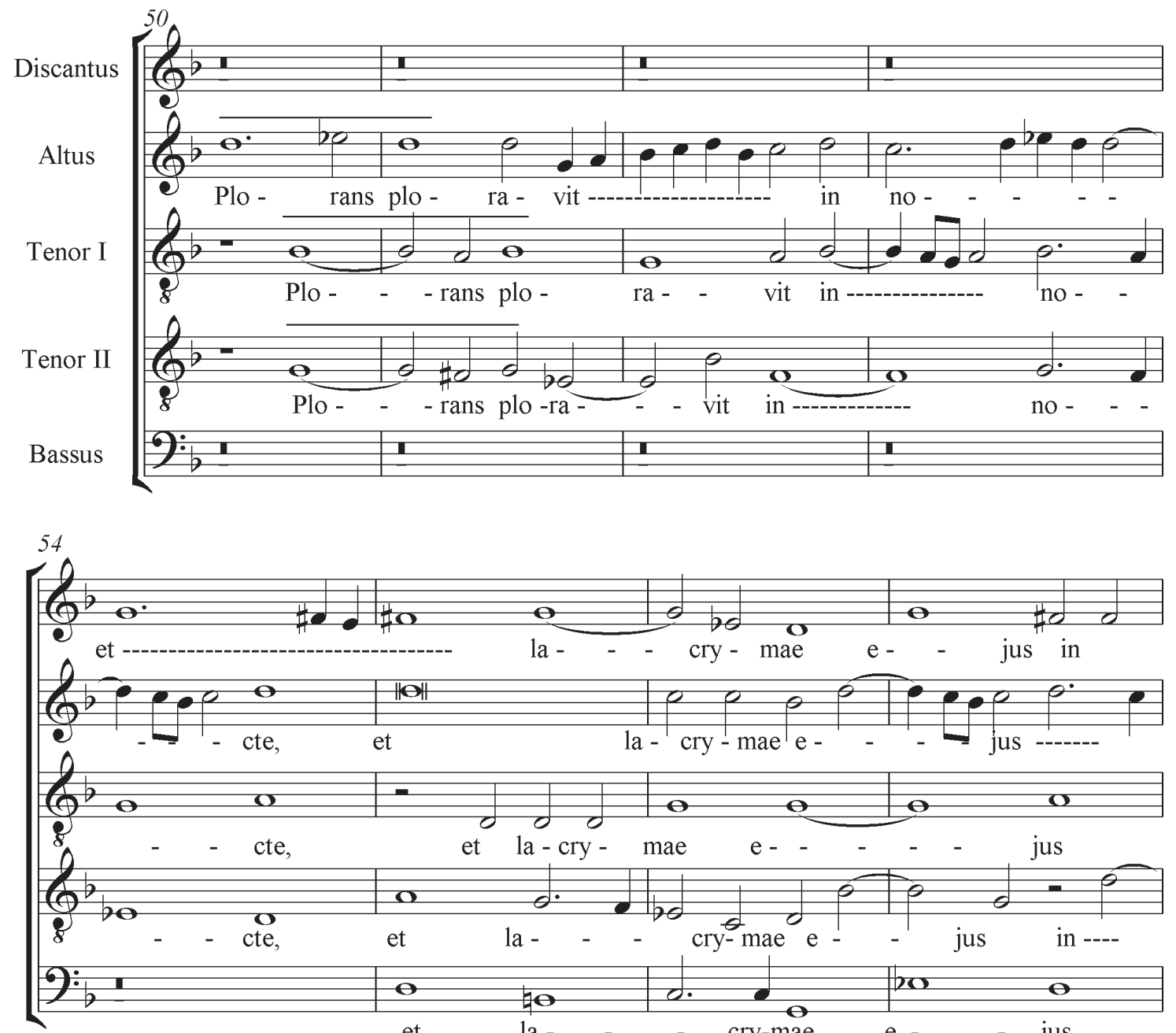

et la - - $\quad$ - cry-mae e - $\quad$ jus 
São apresentados dois exemplos desta figura na obra.

No primeiro (Ex.9), Facta est sub tributo (Lam.1:1; seção 3; c.40-43; ver Tab.1).

Jerusalém, "a princesa das províncias" ( $A$ BÍBLIA DE JERUSALÉM, 2002, p.1460), está sujeita ao tributo. Ao final da primeira lamentação, nas palavras sub tributo, observase esta figura cadencial. Além da syncope também ocorre 0 symblema. BURMEISTER ([1606],1993, p.169) menciona:

Symblema é uma mistura de consonâncias e dissonâncias que acontece da seguinte maneira. Ao início ou primeira metade de um tactus, todas as consonâncias ocorrem como consonâncias absolutas em todas as vozes da harmonia. Contudo, ao final ou segunda metade do tactus, nem todas, mas somente algumas das vozes relacionam-se como consonâncias absolutas. Das vozes que são consonantes entre si, algumas se movem à mesma posição, enquanto outras, permanecem estacionárias por alguns tactus. ${ }^{12}$

A syncope ocorre nas vozes de discantus, altus e tenor II (c.40-42). 0 symblema minus está nas vozes de tenor
I (c.40 e 42), tenor II (c.42). Assim, syncope e symblema ocorrem nas palavras sub tributo. Jerusalém, a senhora das nações, "a princesa das províncias", está sujeita ao tributo. A ocorrência de dissonâncias, através do pleonasmus, revela a seriedade do momento. A harmonia caminha por intervalo diapente ${ }^{13}$ ascendente:

\section{Sub tributo}

$$
\begin{gathered}
\mathrm{Bb}-\mathrm{F}-\mathrm{C}-\mathrm{Gm}-\mathrm{Dm}-\mathrm{A} \\
\text { diapente ascendente }
\end{gathered}
$$

Tab.3 - Encadeamento harmônico (c.40-43) das Lamentationes Jeremiae Prophetae de Orlando Di Lasso

No segundo (Ex.10), Omnes persecutores ejus apprehenderunt eam inter angustias (Lam.1:3; seção 7; compassos 109: final - 110; ver Tab.1).

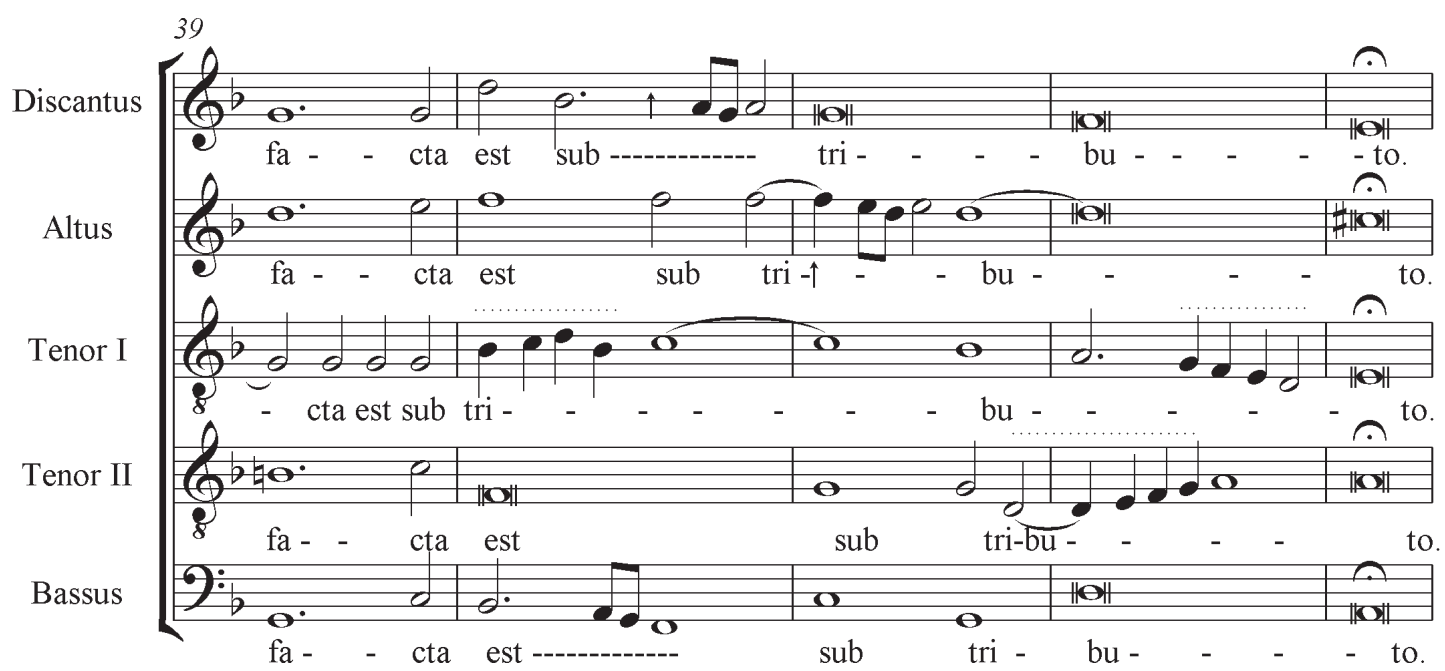

Ex.9 - Pleonasmus (sub tributo) das Lamentationes Jeremiae Prophetae de Orlando Di Lasso

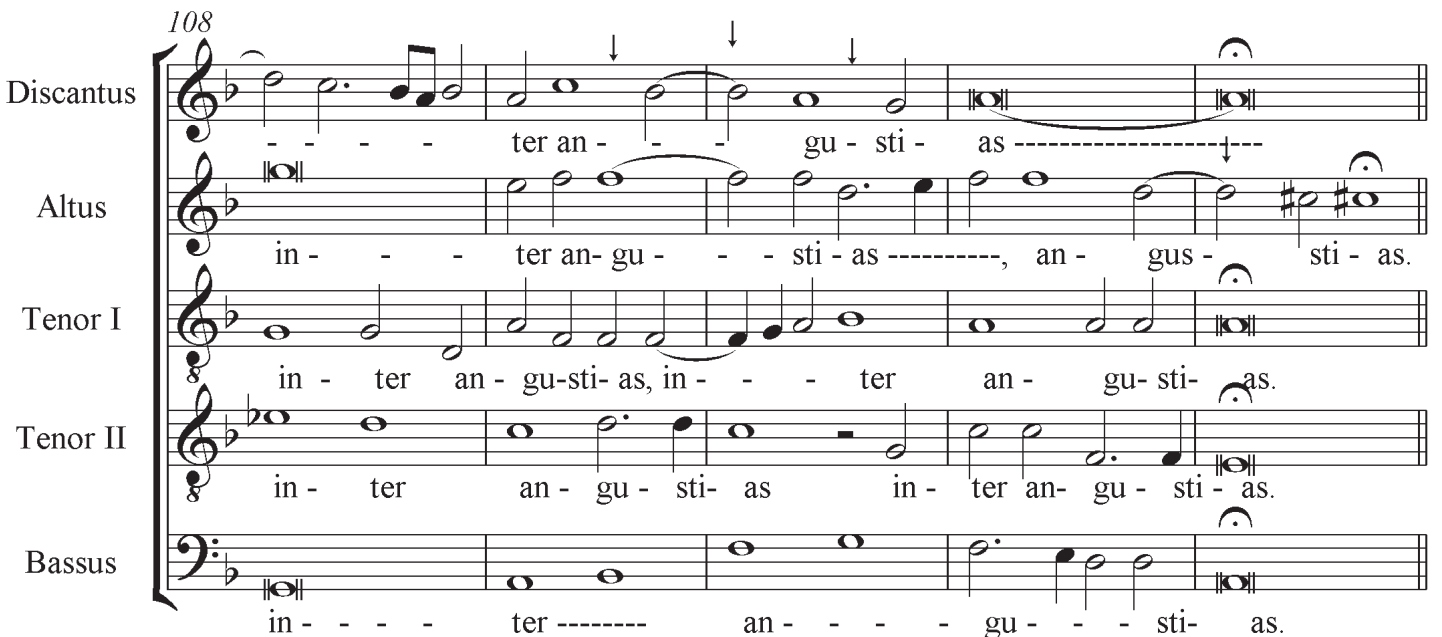

Ex.10 - Pleonasmus (angustias) das Lamentationes Jeremiae Prophetae de Orlando Di Lasso 
$\mathrm{Na}$ palavra angustias pode ser observada três dissonâncias (syncope) seguidas na voz de discantus, o que caracteriza a figura pleonasmus; sons mais longos também podem ser verificados. Tais recursos provocam um efeito suspensivo que caracteriza 0 texto. Outras sincopas podem ser observadas no discantus e altus (início dos compassos 108 e 112, respectivamente).

\section{7 - Congeries (Synathroismos)}

"É o sobrepor de consonâncias perfeitas e imperfeitas, ${ }^{14}$ que prosseguem em movimento similar" (BURMEISTER [1606], 1993, p.185). BARTEL (1997, p.230) citando Burmeister menciona: "... a congeries caracteriza uma alternância entre a triade em posição fundamental e em primeira inversão resultante de sincopas contínuas através de suspensões em uma das vozes, "nas quais movimentos paralelos foram abandonados..."

0 Ex.11 mostra uma ocorrência de congeries, Non est qui consoletur eam (Lam.1:2; seção 5; c.60: final-64; ver Tab.1).

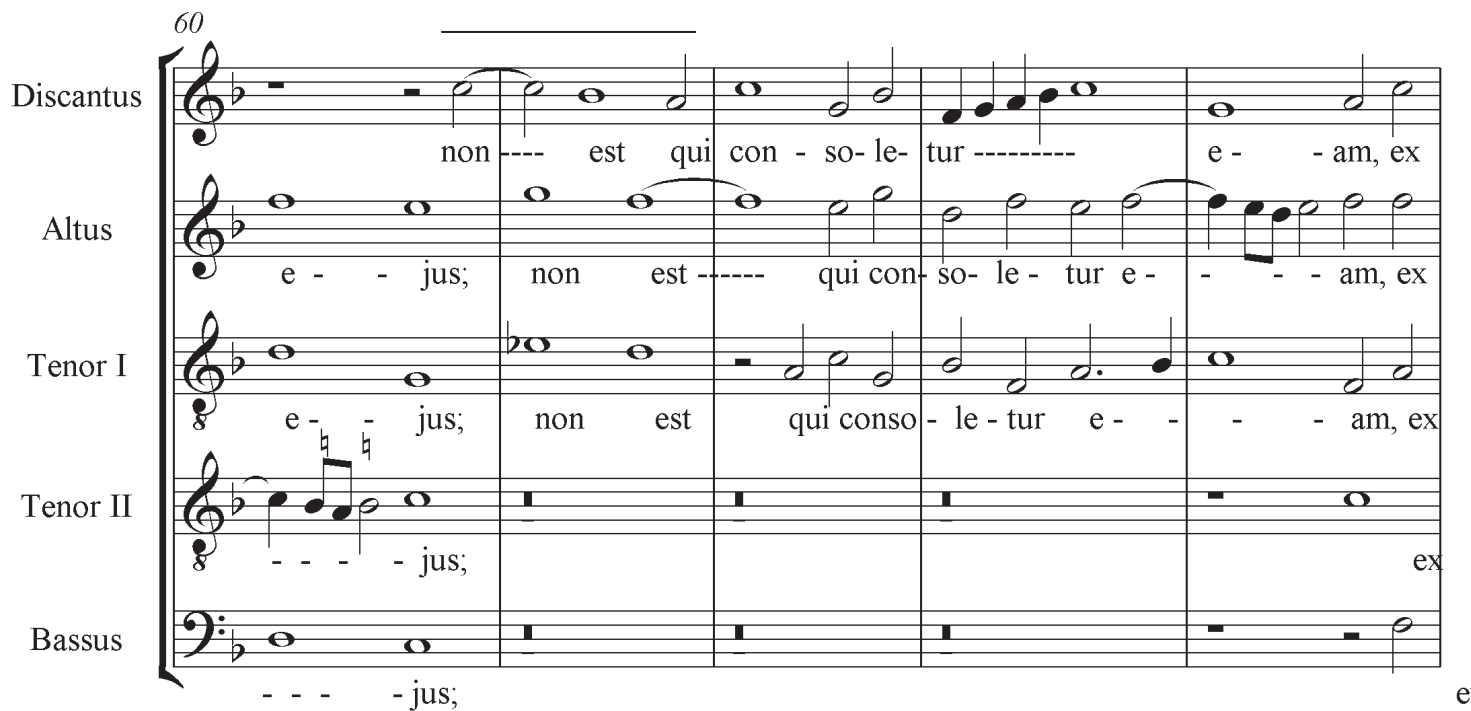

Ex.11 - Congeries (non est qui consoletur eam) das Lamentationes Jeremiae Prophetae de Orlando Di Lasso

A voz de discantus (c.61) traz syncope (duas seguidas), provocando e alongando a suspensão. A alternância das suspensões e resoluções harmônicas desta figura em concordância com o texto, pode ocasionar um efeito de ansiedade e aflição: "não há quem a console" (A BíBLIA DE JERUSALÉM, 2002, p.1460).

\section{Conclusão}

A Tab.4 resume as figuras retórico-musicais analisadas em Lamentatio Prima Primi Diei:

A identificação das figuras é o primeiro passo para a compreensão mais aprofundada do texto e do seu valor

\begin{tabular}{|l|l|l|l|l|}
\hline SEÇÃO & TEXTO & $\begin{array}{l}\text { FIGURAS } \\
\text { RETÓRICO- }\end{array}$ & $\begin{array}{l}\text { RECURSOS } \\
\text { MUSICAIS EM- }\end{array}$ & $\begin{array}{l}\text { AFETO, CARÁTER OU } \\
\text { QUALIDADE }\end{array}$ \\
\hline $\begin{array}{l}\text { Exordium } \\
\text { Ex-12) }\end{array}$ & $\begin{array}{l}\text { Incipit } \\
\text { Lamentatio... }\end{array}$ & Hypallage & $\begin{array}{l}\text { Entradas graduais } \\
\text { do motivo imita- } \\
\text { tivo. } \\
\text { Repetição motívica } \\
\text { em movimento } \\
\text { contrário. }\end{array}$ & $\begin{array}{l}\text { Movimento de iniciar algo } \\
\text { (abertura da obra) }\end{array}$ \\
\hline $\begin{array}{l}\text { Medium } \\
\text { (c.13-18) }\end{array}$ & Aleph & Anaphora & $\begin{array}{l}\text { Motivo melis- } \\
\text { mático tratado } \\
\text { imitativamente com } \\
\text { entradas paulatinas } \\
\text { e sucessivas. }\end{array}$ & $\begin{array}{l}\text { Movimento: principiar do } \\
\text { primeiro versículo. }\end{array}$ \\
\hline \hline
\end{tabular}




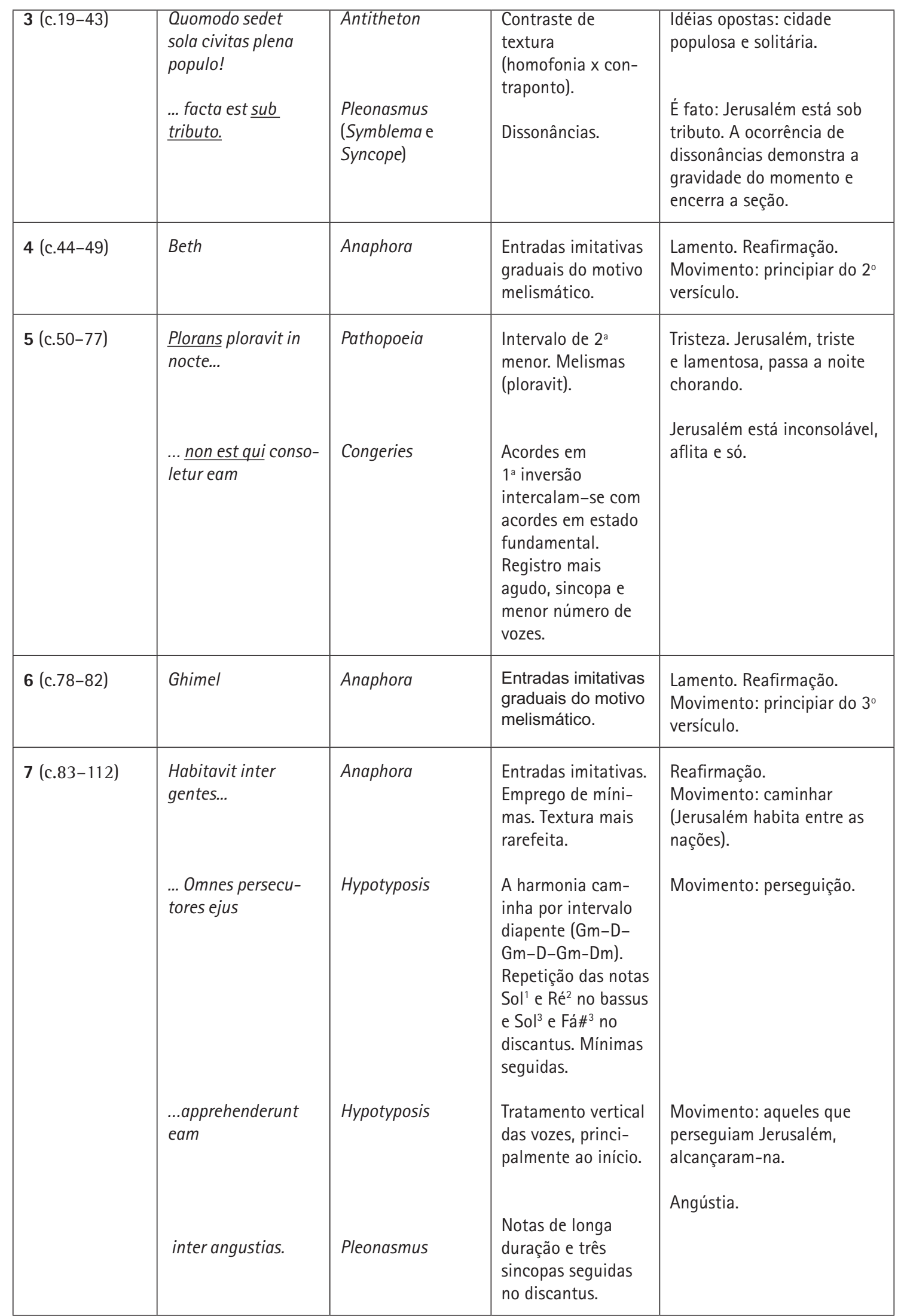

Tab.4 - Figuras retórico-musicais na Lamentatio Prima Primi Diei (Feria Quinta in Coena Domini) de Orlando Di Lasso 
retórico-musical. Contudo, segundo a metodologia analítica empregada por Burmeister (quinta categoria), somente a identificação das figuras não é suficiente para determinar 0 afeto. Para a melhor compreensão da obra, devem-se também encontrar os periodos, presentes nas três partes constitutivas do discurso (exordium, medium e finis).

As cadências (cuja análise é parte do projeto de doutorado) têm um valor estrutural importante, pois elas pontuam os periodos, podendo também apresentar uma qualidade de expressão retórico-musical.

Os elementos que formam a sintaxe da obra (figura, texto, cadências, textura, altura modal, etc), embora distintos, interagem de maneira a sugerir um único sentimento ou afeto.

Os artifícios retóricos não se limitam às figuras, mas são elas, indubitavelmente, ferramentas valiosas na expressão do afeto. A análise de uma obra deste período, buscando conhecer e compreender as figuras retórico-musicais e a sua inserção no contexto geral da obra, pode oferecer aos instrumentistas, cantores e regentes, um importante subsídio interpretativo de época.

Como a definição do poeticum decorum indica, o texto da composição é o fator determinante na aplicação das figuras. Esta visão é também articulada no comentário introdutório às figuras em Musica Poetica: "Se o estudante deseja saber quando e onde a composição deve ser ornamentada com estas figuras, é necessário examinar atentamente o texto de uma composição, especialmente quando usa o ornamento específico e então, ornamentar um texto similar com as mesmas figuras. Deve fazer isto, de tal maneira, que o próprio texto prescreverá as regras." (BARTEL, 1997, p.97).

\section{Referências}

A BíBLIA DE JERUSALEM. São Paulo (Paulus), 2002.

BARTEL, D. Musica Poetica. Lincoln and London: University of Nebraska, 1997.

BENT, I. D.; POPLE, A. Analysis. In: The New Grove Dictionary of Music and Musicians. Stanley Sadie, Ed. London: Macmillan, 1980.

BURMEISTER,J. Musica Poetica. Rostochii: Stephanus Myliander, 1606.

BURMEISTER, J. Musical Poetics (Musica Poetica:1606).Tradução: Benito V. Rivera. New Haven and London: Yale University Press, 1993.

RIVERA, B. V.; RUHNKE, M. Joachim Burmeister. In: The New Grove Dictionary of Music and Musicians.(Stanley Sadie, Ed.). London: Macmillan, v.4, 1980.

SADIE, S. (Ed.). Diapente. The New Grove Dictionary of Music and Musicians. London: Macmillan, v. 7, 1980.

WILSON, B., BUELOW, G. J. e HOYT, P. A. Rethoric and Music. In: The New Grove Dictionary of Music and Musicians. (Stanley Sadie, Ed.). London: Macmillan, v.21, 1980.

\section{Partitura}

LASSO, 0. DI. Lamentationes Jeremiae Prophetae: vocal. Kassel: Bärenreiter, ${ }^{\odot 1992 . ~} 1$ partitura (259 p.). Discantus, altus, tenor e bassus.

\section{Documento sonoro}

LASSUS, R. de: Hieremiae Prophetae Lamentationes. Direção: Phillippe Herreweghe. Intérpretes: Ensemble Européen De La Chapelle Royale.

Harmonia Mundi, p1989. 1 CD.

Áurea Helena de Jesus Ambiel, regente, professora de disciplinas teórico-musicais, é doutoranda em musicologia histórica pela Universidade Estadual de Campinas, e tem como orientadora, a profa. Dra. Helena Jank. É mestre em Artes pela mesma Universidade.

Notas

BURMEISTER [1606], 1993, p.201.

BURMEISTER [1606], 1993, p.201.

(LASSUS, 2003, p.7)

"Autores clássicos variavam em suas numeracões das partes de um discurso. Rhetorica ad Herennium 1.3.4 lista seis partes: exordium, narratio, divisio, confirmatio, confutatio e conclusio. A mais ampla divisão tripartida era, obviamente, inspirada pela injunção de Aristóteles que, um drama trágico ou poema épico, para ser um todo unificado, deveria ter um começo [arche], meio [meson] e fim [teleute] (Aristóteles, Poetics 7.3 e 23.1). Uma comparação da parte média a um corpo humano é encontrado em Aristóteles, Rethoric 3.14.8: "Se o ouvinte já está bem disposto (preparado), não haveria necessidade de um exórdio, exceto para sumariar o sujeito da fala, de maneira que, como um corpo [soma], ele pode ter uma cabeça." Capítulos 12, 13 e 14 de Praecepta de Dressler, provém diretrizes sobre a estruturação do exordium, medium e finis." Nota de rodapé $\mathrm{n}^{\circ} 2$ (BURMEISTER [1606],1993, p.203). 
5 "Imitação fugal em movimento contrário" (WILSON, BUELOW, HOYT,1980, v.21, p.265).

6 Discantus é a voz mais aguda da obra.

7 Ver exemplo 8.

8 BARTEL (1997, p.309) cita ainda: "0 termo hypotyposis é encontrado uma vez mais no Conclave de Vogt. Vogt não o inclui na sua lista de figuras, mas preferivelmente usa o termo para caracterizar geralmente suas figuras ideales. Estas figuras não são somente para expressar os afetos, mas são para apresentar a idea do texto de uma maneira real (vivaciter) e imaginativa (idealiter). Para este fim o compositor usa as figuras hypotyposis e prosopopoeia. Com estas instruções Vogt tipifica sua categoria de figuras ideales. A formulação plural de figurae hypothiposeos sugere uma classe inteira de tais figuras. Este entendimento é sustentado pela definição anterior de Vogt de idea musica como "aquilo que é retratado através das figuras de hypotyposis." Música e palavra juntas são para a obra uma vivida representação da ("aquilo que é visto") do texto, usando figurae ideales hypotyposeos."

9 Nota de rodapé: letra a).

10 Nota de rodapé número 33 (BURMEISTER [1606], 1993, p.175).

11 "Um tactus, não deve ser confundido com o moderno Takt alemão, tem a duração de uma semibreve; duas semibreves fazem uma medida ou perfeição" (BURMEISTER, [1606], 1993, p.29; nota de rodapé n8).

12 BARTEL (1997, p.418-419) cita Burmeister (Musica Poetica, p.60): Symblema é uma mistura de consonâncias e dissonâncias que acontece na seguinte maneira. Ao início ou primeira metade de um tactus, todas as consonâncias ocorrem como consonâncias absolutas em todas as vozes da harmonia. Contudo, ao final ou segunda metade do tactus, nem todas, mas somente algumas das vozes relacionam-se como consonâncias absolutas. Das vozes que são consonantes entre si, algumas movem-se à mesma posição, enquanto outras, permanecem estacionárias por alguns tactus. ${ }^{13}$

Diapente: "(do Gk. dia pente: 'através de cinco'). Na Grécia antiga e medieval, nome dado ao intervalo de uma quinta. Nos tratados medievais e nos manuscritos musicais, os termos epidiapente (' 5 a acima') e subdiapente (hypodiapente ' 5 a abaixo') são usados para designar canons a uma quinta superior ou inferior respectivamente."' (SADIE (Ed.), 1980, v.7, p.292).

14 Isto é, terças imperfeitas posicionadas sobre quartas perfeitas (citação de rodapé número 50 em BURMEISTER [1606], 1993, p. 185). 